\title{
WEIGHTED COMPOSITION OPERATORS FROM WEIGHTED BERGMAN SPACES TO STEVIĆ-TYPE SPACES
}

\author{
Xiangling ZHu And JUnTAO DU
}

Abstract. The boundedness, compactness and essential norm of weighted composition operators from weighted Bergman spaces with a double weight to Stević-type spaces on the unit disk are investigated in this paper.

Mathematics subject classification (2010): 30H10, 47B33.

Keywords and phrases: Weighted composition operator, weighted Bergman space, Stević-type space, double weight.

\section{REFERENCES}

[1] F. Colonna, New criteria for boundedness and compactness of weighted composition operators mapping into the Bloch space, Cent. Eur. J. Math. 11 (2013), 55-73.

[2] F. Colonna AND M. TJANI, Weighted composition operators from the Besov spaces into the weighted-type space $H_{\mu}^{\infty}$, J. Math. Anal. Appl. 402 (2013), 594-611.

[3] F. COLONNA AND M. TJANI, Operator norms and essential norms of weighted composition operators between Banach spaces of analytic functions, J. Math. Anal. Appl. 434 (2016), 93-124.

[4] M. Contreras And A. HernandeZ-Diaz, Weighted composition operators in weighted Banach spaces of analytic functions, J. Aust. Math. Soc. A 6 (2000), 41-60.

[5] C. Cowen And B. MacCluer, Composition Operators on Spaces of Analytic Functions, CRC Press, Boca Raton, FL, 1995.

[6] J. DU, S. LI AND Y. ZHANG, Essential norm of generalized composition operators on Zygmund type spaces and Bloch type spaces, Ann. Polon. Math. 119 (2017), 107-119.

[7] J. DU, S. Li AND Y. ZHANG, Essential norm of weighted composition operators on Zygmund-type spaces with normal weight, Math. Ineq. Appl. 21 (2018), 701-714.

[8] P. GALINDO, J. LAitila AND M. LindSTRÖM, Essential norm estimates for composition operators on BMOA, J. Funct. Anal. 265 (2013), 629-643.

[9] P. Galindo, M. Lindström And S. STEvić, Essential norm of operators into weighted-type spaces on the unit ball, Abstr. Appl. Anal., vol. 2011, Article ID 939873, (2011), 13 pages.

[10] Q. HU AND X. ZHU, Essential norm of weighted composition operators from the Lipschtiz space to the Zygmund space, Bull. Malays. Math. Sci. Soc. 41 (2018), 1293-1307.

[11] T. Hosokawa, Differences of weighted composition operators on the Bloch spaces, Complex Anal. Oper. Theory 3 (2009), 847-866.

[12] T. Hosokawa AND S. OHno, Differences of weighted composition operators acting from Bloch space to $H^{\infty}$, Trans. Amer. Math. Soc. 363 (2011), 5321-5340.

[13] S. Li AND S. STEVIĆ, Weighted composition operators from Bergman-type spaces into Bloch spaces, Proc. Indian Acad. Sci. Math. Sci. 117 (2007), 371-385.

[14] S. Li And S. STEVIĆ, Weighted composition operators between $H^{\infty}$ and $\alpha$-Bloch spaces in the unit ball, Taiwanese J. Math. 12 (2008), 1625-1639.

[15] S. Li And S. STEVIĆ, Weighted composition operators from Zygmund spaces into Bloch spaces, Appl. Math. Comput. 206 (2008), 825-831.

[16] S. Li AND S. STEvić, Composition followed by differentiation between $H^{\infty}$ and $\alpha$-Bloch spaces, Houston J. Math. 35 (2009), 327-340. 
[17] S. LI AND S. STEVIĆ, Products of integral-type operators and composition operators between Blochtype spaces, J. Math. Anal. Appl. 349 (2009), 596-610.

[18] S. Li And S. STEvić, Generalized weighted composition operators from $\alpha$-Bloch spaces into weighted-type spaces, J. Ineq. Appl. 2015 (2015), 1-12.

[19] S. Li AND S. STEVIĆ, Weighted differentiation composition operators from the logarithmic Bloch space to the weighted-type space, An. Stiint. Univ. "Ovidius" Constanta Ser. Mat. 24 (2017), $223-$ 240.

[20] B. MACCLUER AND R. ZHAO, Essential norm of weighted composition operators between Bloch-type spaces, Rocky. Mountain J. Math. 33 (2003), 1437-1458.

[21] A. Montes-Rodriguez, Weighed composition operators on weighted Banach spaces of analytic functions, J. London Math. Soc. 61 (2000), 872-884.

[22] S. OHNO, Weighted composition operators between $H^{\infty}$ and the Bloch space, Taiwanese J. Math. 5 (2001), 555-563.

[23] J. PelÁEZ, Small weighted Bergman spaces, arXiv: 1507.07182 [math. CV], 2015.

[24] J. PelÁEZ AND J. RätTyÄ, Weighted Bergman spaces induced by rapidly increasing weights, Mem. Amer. Math. Soc. 227 (1066) (2014).

[25] J. PeláEZ And J. RÄTtYÄ, Embedding thorems for Bergman spaces via harmonic analysis, Math. Ann. 362 (2015), 205-239.

[26] J. PeláeZ And J. RÄTty Ä, Trace class criteria for Toeplitz and composition operators on small Bergman space, Adv. Math. 293 (2016), 606-643.

[27] B. Sehba And S. STEvić, On some product-type operators from Hardy-Orlicz and Bergman-Orlicz spaces to weighted-type spaces, Appl. Math. Comput. 233 (2014), 565-581.

[28] S. STEvić, Composition operators from weighted Bergman space to $n$-th weighted space on the unit disk, Discrete Dyn. Nat. Soc. Vol. 2009 (2009), Article ID 742019, 11 pages.

[29] S. STEVIĆ, On an integral-type operator from logarithmic Bloch-type and mixed-norm spaces to Bloch-type spaces, Nonlinear Anal. TMA 71 (2009), 6323-6342.

[30] S. Stević, On new Bloch-type spaces, Appl. Math. Comput. 215 (2009), 841-849.

[31] S. Stević, Products of composition and differentiation operators on the weighted Bergman space, Bull. Belg. Math. Soc. Simon Stevin 16 (2009), 623-635.

[32] S. STEVIĆ, Weighted differentiation composition operators from mixed-norm spaces to weighted-type spaces, Appl. Math. Comput. 211 (2009), 222-233.

[33] S. STEvić, Composition followed by differentiation from $H^{\infty}$ and the Bloch space to $n$-th weightedtype spaces on the unit disk, Appl. Math. Comput. 216 (2010), 3450-3458.

[34] S. STEVIĆ, On operator $P_{\varphi}^{g}$ from the logarithmic Bloch-type space to the mixed-norm space on unit ball, Appl. Math. Comput. 215 (2010), 4248-4255.

[35] S. STEVIĆ, Weighted differentiation composition operators from $H^{\infty}$ and Bloch spaces to $n$-th weighted-type spaces on the unit disk, Appl. Math. Comput. 216 (2010), 3634-3641.

[36] S. STEviĆ, Weighted differentiation composition operators from the mixed-norm space to the $n$-th weigthed-type space on the unit disk, Abstr. Appl. Anal., vol. 2010 (2010), Article ID 246287, 15 pages.

[37] S. STEVIĆ, Essential norm of some extensions of the generalized composition operators between $k$-th weighted-type spaces, J. Ineq. Appl. 2017 (2017), 220.

[38] S. Stević, A. K. Sharma AND A. Bhat, Products of multiplication composition and differentiation operators on weighted Bergman spaces, Appl. Math. Comput. 217 (2011), 8115-8125.

[39] M. TJAnI, Compact composition operators on some Möbius invariant Banach spaces, PhD dissertation, Michigan State University, 1996.

[40] M. ZHANG AND H. CHEN, Weighted composition operators of $H^{\infty}$ into $\alpha$-Bloch spaces on the unit ball, Acta Math. Sin. (Engl. Ser.) 25 (2009), 265-278.

[41] L. Zhang AND H. ZENG, Weighted differentiation composition operators from weighted Bergman space to $n$-th weighted space on the unit disk, J. Ineq. Appl. 2011 (2011), 10 pages.

[42] K. ZHU, Bloch type spaces of analytic functions, Rocky Mountain J. Math. 23 (1993), 1143-1177.

[43] K. ZHU, Operator Theory in Function Spaces, 2ed edition, Math. Surveys and Monographs, vol. 138, American Mathematical Society: Providence, Rhode Island, 2007.

[44] X. ZHU, Generalized weighted composition operators on Bloch-type spaces, J. Ineq. Appl. 2015 (2015), 59-68. 
[45] X. ZHU, Essential norm of generalized weighted composition operators on Bloch-type spaces, Appl. Math. Comput. 274 (2016), 133-142. 